\title{
Forces on piles preventing debris slope slips
}

\author{
J. Vacek \& S. Hrachová \\ Czech Technical University, Klokner Institute, Czech Republic
}

\begin{abstract}
Failure of rock mass is not a static process, but has its own history. Its duration varies from several seconds to several hundreds of years. Rock mass movements often reach hundreds of metres and significantly change their original shape. Failure mechanics can be studied experimentally. We can observe the onset of failure on nonhomogeneous models (prior to and during the failure, during the increase of deformations on sliding surfaces), the chronology of various stages of failure (cavings, slides), and the final shape of the rock mass. We can also observe influences, exerted by modelled joints, adits and other features, upon the failure history and shapes of cavings and slides.

Research will be concentrated on the stability of internal tailings of Northern Bohemia open coal mines. There is a very smooth plane between the tailings and the bedrock. It was built up during mining, while being exposed to weather attacks, such as rain, frost and sun shine, and it was plastificated by the movement of mining machines. Tailings will be strengthened by piles that join bedrock with tailing over the predestinated slip plane.

Methods used for the study of geotechnical problems have to allow for it to be studied on the basis of two presumptions:
\end{abstract}

- results must be time dependent

- results must allow the creation of joints in the rock mass before and during the study of the event and they have to allow for the movement of rock along joints, the opening of joints and the creation of new joints. The direction of the modelled joints must be similar to the reality, i.e. their direction and inclination must be the same as in reality. These measures make it possible to create a structure of modelled rock mass similar to the real one. The filling of cracks must be equivalent to those in reality.

The scale of physical models was used as a basic method of study of geotechnical problems from equivalent materials and a mathematical solution.

Keywords: failure mechanics, physical model, mathematical model, pile defence of slope slip. 


\section{Introduction}

The present study deals with the failure mechanics of the slope build-up on bedrock with a smooth surface. This arrangement is typical for the internal tailings in the surface of coal mines. The experimental study was constructed in a stand enabling tilting. A scale model was constructed from equivalent materials. The smooth surface was made from a special epoxy resin. For the mathematical part, the particle flow code in two dimensions $\left(\mathrm{PFC}^{2 \mathrm{D}}\right)$ was employed. The pile was bored to the bedrock, instrumented with strain gauges, and the slope movement was restrained in the experimental case. Ten fixed balls were considered in the mathematical solution. Both methods have shown the slip as a time dependent process. Moreover, both methods describe a decomposition of the original homogeneous and isotropic body into blocks (see Figs 2 and 3) and, therefore, they treat the slip as a discontinuous deformation process.

The stability of mine tailings situated on an inclined terrain is often influenced by a predestinated slip surface represented by the contact between the terrain surface and tailings. The speed of movements of Loket or Vintírov tailings was about $1 \mathrm{~m}$ in a day during the slip. Piles were bored down to the bedrock and jointed the tailings with the original terrain in order to strengthen the critical shear plane.

\section{Experimental models}

Physical scale models made from equivalent materials were utilized for an experimental study of the problem. The model was built-up from three types of material: the bedrock consisted of a mixture of 100 weight parts of melted limestone, 4 w.p. of cement and 4 w.p. of water. The predestined shear surface was made of specifically adapted epoxy resin. The angle of its internal friction and the long time cohesion equals zero. It behaves as a liquid with a high viscosity. Tailings were made of the mixture of melted limestone 100 w.p. with grease 0,5 w.p. The pile was represented by a polyethylene pipe with a diameter of $18 \mathrm{~mm}$, provided with three pairs of strain gauges, connected to the tensometrical bridge. This arrangement enables one to measure the force with which the pile resists the tailings slip. The model dimensions were: length $1450 \mathrm{~mm}$, height $-600 \mathrm{~mm}$, width $-200 \mathrm{~mm}$. Before the test, the stand was tilted $10^{\circ}$ from the horizontal plane (see Figure 2).

\section{Test results}

Figure 1 represents a photograph of the model before the test. Figure 2 shows the model at a time $t_{0}+30$ minutes. Figure 3 depicts the model at a time $t_{0}+70 \mathrm{~h}$ and Figure 4 at a time $t_{o}+140 h$. The photos clearly reveal the cracks in the tailing body. Figure 5 displaces a change of the slip surface during the test. Figure 6 shows the measured total force with which the slope acts on the pile and the 
actual height of the filling up of the pilot. Figure 7 shows the load distribution on the pile during the test. The figures show that the defend force is not the simple function of height $\mathrm{H}$. This fact is caused by the creation or breaking of the arch effect in the slip material.

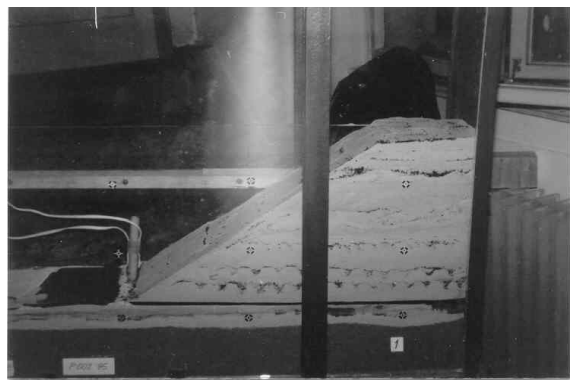

Figure 1: $\quad$ Model before test, $\mathrm{t}_{\mathrm{o}}=\mathrm{O}$.
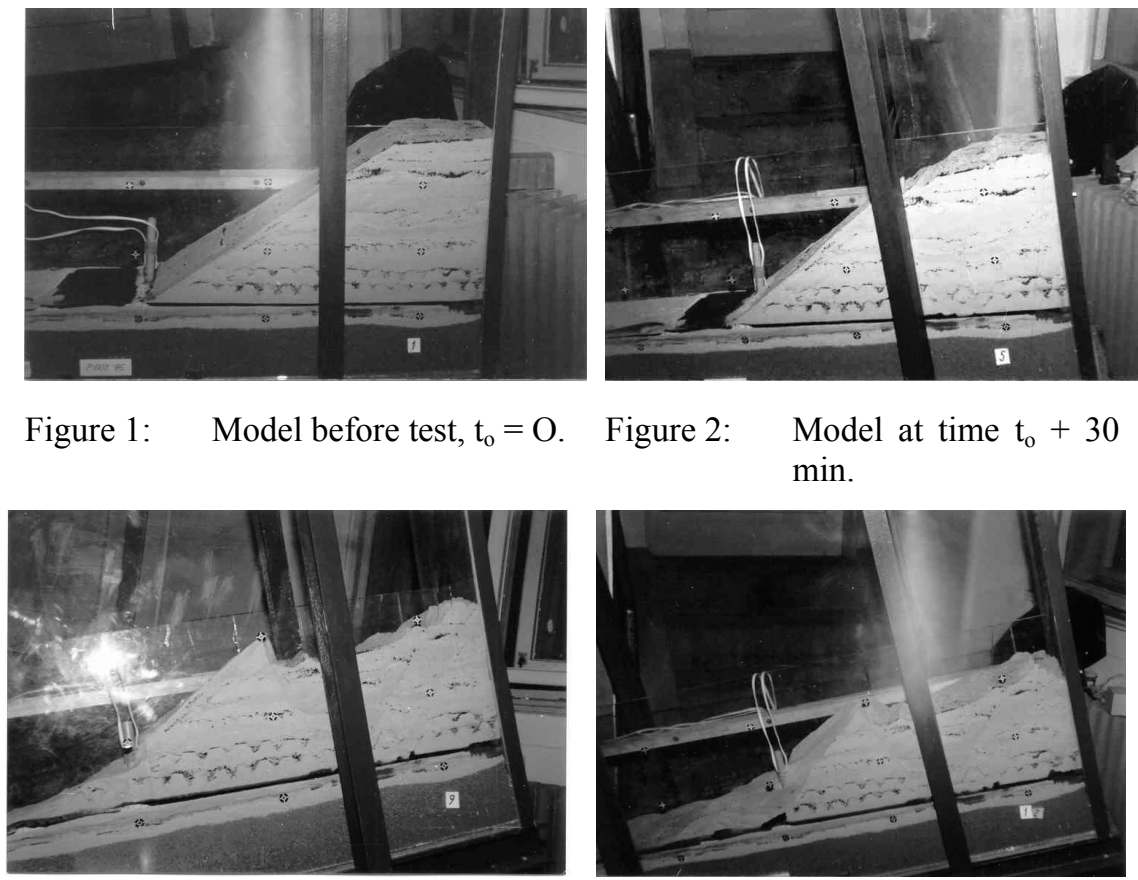

Figure 3: $\quad$ Model at time $\mathrm{t}_{\mathrm{o}}+70 \mathrm{~h}$.
Figure 2: $\quad$ Model at time $\mathrm{t}_{\mathrm{o}}+30$ $\min$.

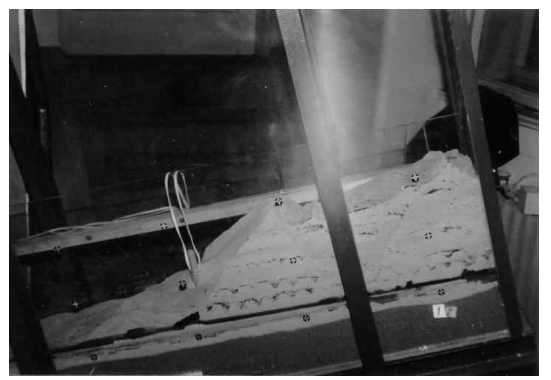

Figure 4: Model at time $t_{0}+$ $140 \mathrm{~h}$.

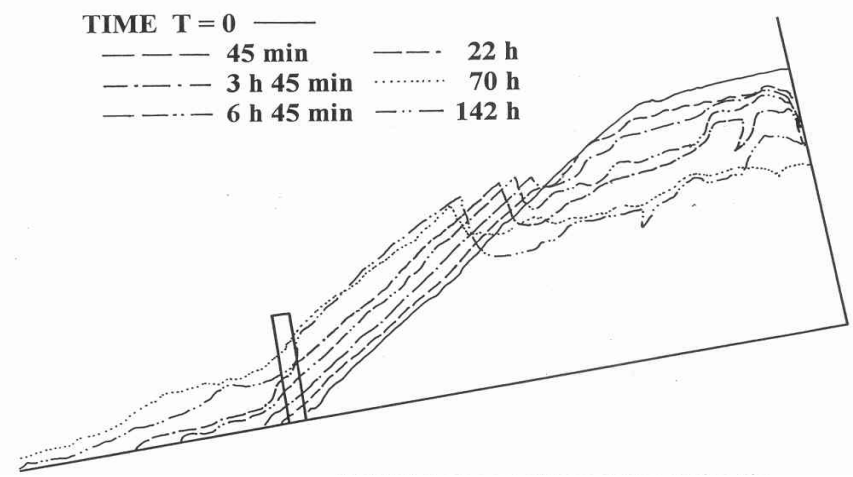

Figure 5: Experimental results. Changes of the tailing surface during the slip and the height of the slope that loads the pile in different stages of the slide are clearly visible. 


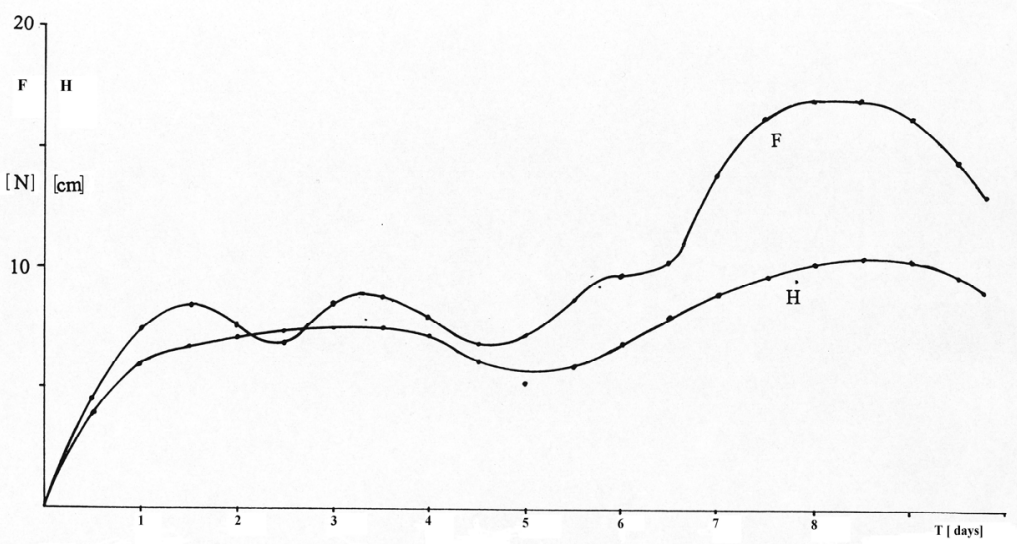

Figure 6: Experimental results. Force F with which the pile defends the slip as a function of height $\mathrm{H}$. Slope height $\mathrm{H}[\mathrm{cm}]$ acts as the $\mathrm{a}^{+}$pile and the total force is denoted by $\mathrm{F}[\mathrm{N}]$, by which the pile defends the slope slip at time $\mathrm{T}$ [days].

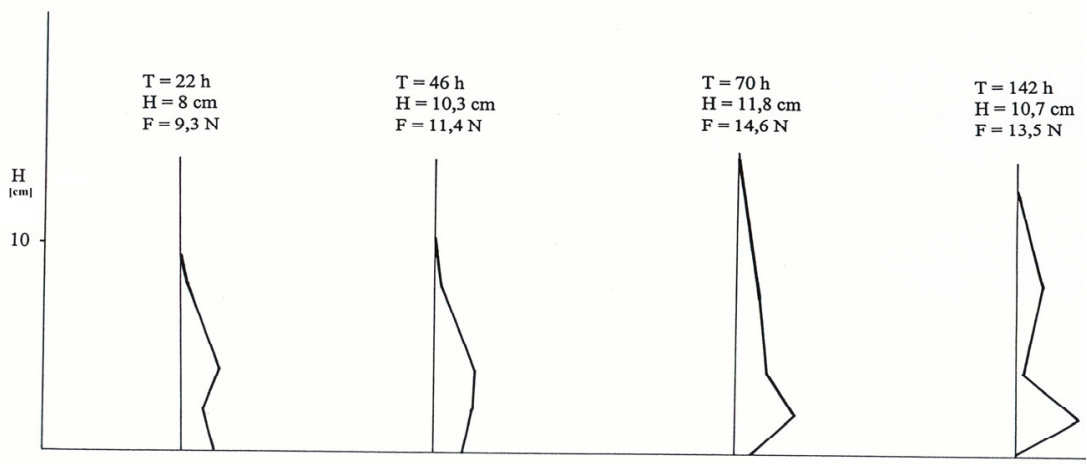

Figure 7: $\quad$ Experimental results: load distribution on pile length and time.

\section{Mathematical study}

For the mathematical study, the $\mathrm{PFC}^{2 \mathrm{D}}$ numerical code was used. The figures depict the original shape and the state after 50000 and 400000 cycles. The creation of cracks in the tailing body is well visible.

These were used for numerical models involving large scale deformations. In addition to following the mechanics and history of decomposition from the point of view of large scale deformations, the PFC code enabled us to observe the sliding mass displaced mostly by shear and tension joints analogous to those observed in the laboratory model of the slip. The numerical analysis provides a 
more accurate approximation and therefore more realistic representation of reality.

The pile was represented by ten balls in the numerical model (see detail in Fig. 10). These balls were fixed to prevent sliding and rotation during the calculation. The size and distance of the balls were changed until the PFC results corresponded to those obtained experimentally. The balls that represent the slope could slide among the balls of the pile during the slide, which corresponds to the slope flowing around the pile in the (three-dimensional) laboratory experiment.

Table 1 shows the forces acting on each of the balls in several phases of the slide, as well as the height at which the material was piled up at the pile in percentage of pile length, the number of cycles in the computation and the total horizontal force and moment of force at the toe of the pile, which the pile was exerting on the slope to resist the slide.

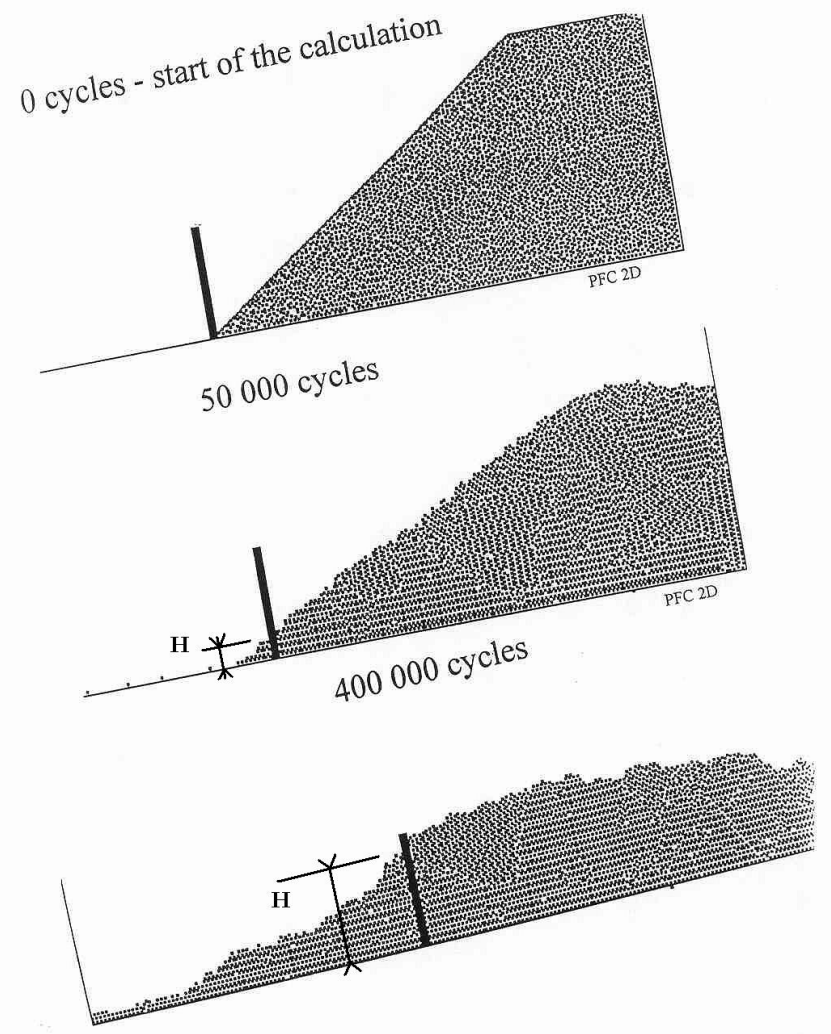

Figure 8: $\quad$ Change of tailing body during the slip. The created cracks are well visible. $\mathrm{H}$ denotes the height of the pile filling up. 
Table 1: $\quad$ Pile contact forces.

\begin{tabular}{|c|c|c|c|c|c|c|c|c|c|c|}
\hline \multicolumn{2}{|c|}{$\begin{array}{l}\text { Height of filling } \\
\text { up of pile [\%] }\end{array}$} & 0 & 48 & 70 & 83 & 92 & 96 & 103 & 104 & 105 \\
\hline \multicolumn{2}{|c|}{$\begin{array}{l}\text { number } \\
\text { of cycles }\end{array}$} & 0 & $100 \cdot 10^{3}$ & $200 \cdot 10^{3}$ & $300 \cdot 10^{3}$ & $400 \cdot 10^{3}$ & $500 \cdot 10^{3}$ & $600 \cdot 10^{3}$ & $700 \cdot 10^{3}$ & $800 \cdot 10^{3}$ \\
\hline \multirow{10}{*}{$\begin{array}{l}\text { ball } \\
\text { no. }\end{array}$} & 1 & 0.0 & 0.0 & 3.5 & 3.2 & 0.0 & 0.0 & -0.5 & -1.6 & 1.3 \\
\hline & 2 & 0.0 & 9.0 & -0.3 & 18.1 & 22.2 & 18.9 & 2.1 & 24.7 & 1.2 \\
\hline & 3 & 0.0 & 0.0 & 2.6 & 8.0 & 2.3 & 3.9 & -0.1 & 2.3 & 0.6 \\
\hline & 4 & 0.0 & 5.1 & 0.0 & 12.3 & 2.9 & 0.0 & 0.3 & -1.2 & 18.9 \\
\hline & 5 & 0.0 & 0.0 & 0.3 & 0.0 & 1.5 & 2.9 & 7.4 & 6.3 & 1.7 \\
\hline & 6 & 0.0 & 0.0 & -0.3 & 0.1 & 2.2 & 0.5 & 0.0 & 1.2 & 3.4 \\
\hline & 7 & 0.0 & 0.0 & 0.0 & 1.3 & 0.5 & 7.9 & 3.2 & 0.1 & -0.1 \\
\hline & 8 & 0.0 & 0.0 & 0.0 & 0.4 & -0.1 & 7.6 & 0.0 & 0.9 & -0.1 \\
\hline & 9 & 0.0 & 0.0 & 0.0 & 0.0 & 1.3 & 0.0 & 2.5 & 9.0 & 0.7 \\
\hline & 10 & 0.0 & 0.0 & 0.0 & 0.0 & 0.0 & 0.0 & 0.0 & 0.1 & 0.3 \\
\hline \multicolumn{2}{|c|}{$\mathrm{x}$-force $[\%]$} & 0.0 & 14.2 & 5.9 & 43.4 & 32.7 & 41.6 & 14.8 & 41.9 & 27.9 \\
\hline \multicolumn{2}{|c|}{ moment } & 0.000 & 0.005 & 0.001 & 0.018 & 0.014 & 0.031 & 0.016 & 0.030 & 0.020 \\
\hline
\end{tabular}

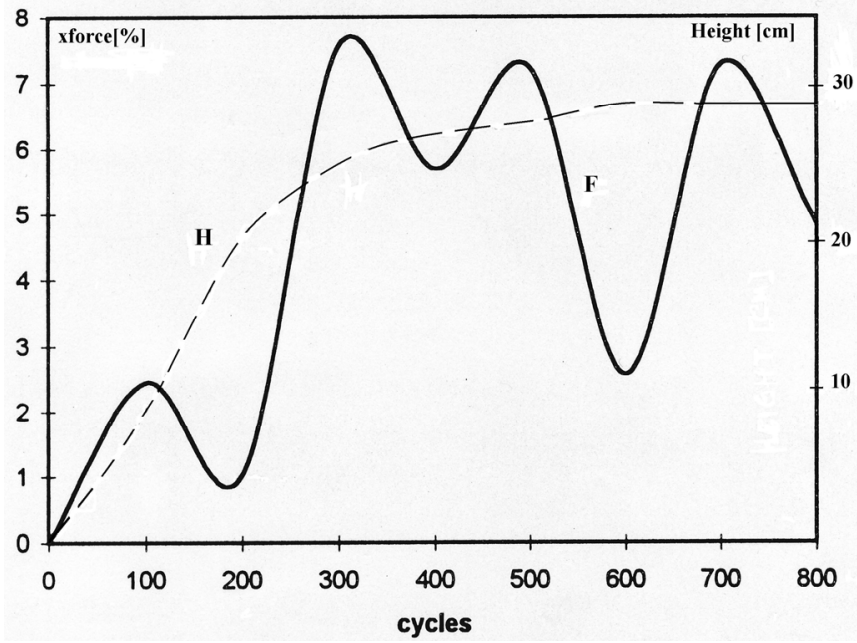

Figure 9: $\quad$ Horizontal force exerted by the pile resisting the slide.

Fig. 9 shows how the total horizontal force depends on the number of iterations. We can see that the force does not grow uniformly. After reaching a maximum after 300000 cycles it alternately decreases and increases within the range of $25 \%$ to $100 \%$ of the maximum value, depending on the creation of rock arches among the balls. We observed similar fluctuations of the force during ground tests as well.

Again similar to the experimental results force, the pile's defence to slip is not determinated by the height of the filling up of the pile. 
Figure 10 shows the penetration of the slope material through the pile, represented by the small balls. Figure 11 shows the distribution on pile length during the test.

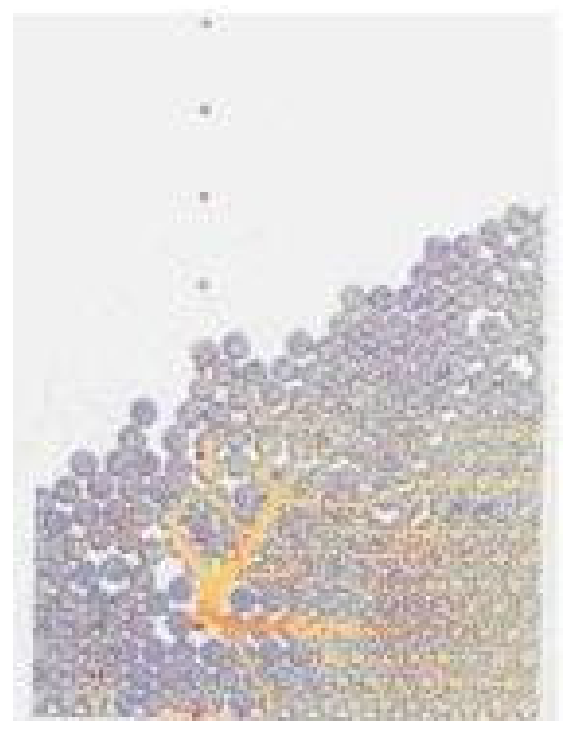

Figure 10: Detail view of inter-ball forces and penetration of slope material among the pile balls.
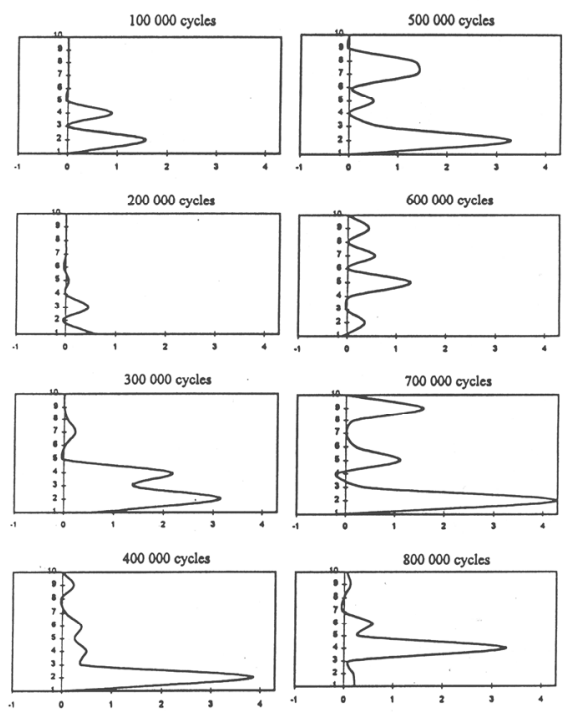

Figure 11: Pile loadings at different cycle numbers. 


\section{Conclusions}

Understanding the failure mechanism and its evolution or history in jointed rock mass is of great importance to the development of the geophysical sciences. In the present paper, we utilized both experimental and theoretical methods to gain such understanding.

Experimental studies on physical models make it possible to investigate the failure problem continuously in time. During the modelling we can observe the changing failure shape, slide duration and final shape of the slope after the failure (cf. Figs. 1-7). Continuous video recording enables us to identify failure symptoms and to more precisely estimate the deformations that signal hazard conditions. Analogous investigations can be carried out on surface subsidence due to underground mining, on tunnel head stability and other failure problems in structural (jointed) rock mass. If the correctness of behaviour of such models is verified on tentative models before the final test is performed, the test agreement with practical conditions is very good.

The mathematical methods available at present can describe the failure as a time dependent process too. Crack creation can also be observed in these models.

Our study mainly reveals that in both investigation methods:

(i) the defend force is not a simple function of the filling up height

(ii) the pile loading on its length is complicated too. This is due to the creation and destruction of arches between the slip material and pile during the failure process.

\section{Acknowledgement}

This paper has been sponsored by GAČR 103/08/0922.

\section{References}

[1] Vacek, J., Procházka, P.: Behaviour of brittle rock in extreme depth. In:"25 $5^{\text {th }}$ Conference on Our World in Concrete Structures", (Editor: Dr C T Tam), Singapore, 2000, pp 653-660

[2] Vacek, J.: Aplikovaná geotechnika (apply geotechnics) (editor: VIP Univ. Pardubice), Pardubice,2000, pp. 1-30

[3] Vacek, J.: Stress Distribution in Coal Seam before and after Bump Initiation (editor: CTU in Prague), Acta Polytechnica, vol.41, No 4-5/2001, pp. 54-60 